\title{
FORMAÇÃO CONTINUADA DE PROFESSORES DO ENSINO FUNDAMENTAL: UM DESAFIO CRIATIVO NA CONTEMPORANEIDADE
}

\author{
Maria José da Silva Morais \\ Universidade Federal do Tocantins - (UFT). Santo André, Brasil \\ Maria José de Pinho \\ Universidade Federal do Tocantins - (UFT). Palmas, Brasil
}

\begin{abstract}
Resumo. Este artigo tem como objetivo analisar a formação continuada dos professores do Ensino Fundamental, da Escola Municipal de Tempo Integral Daniel Batista (Tocantins - Brasil), a partir dos indicadores do Instrumento de Identificação do Desenvolvimento Criativo de Instituições de Ensino (Vadecrie). O referencial metodológico, com ênfase qualitativa, apoiou-se no estudo de caso e nas pesquisas exploratória e documental. Na coleta de dados, a aplicação do Vadecrie foi complementada pela realização de entrevista semiestruturada, observação em campo e análise documental. Os resultados revelam que a formação continuada ocorre a partir das necessidades locais, sendo os professores protagonistas do processo formativo, possibilitando à instituição aperfeiçoar suas potencialidades e superar adversidades. Nesse ínterim, a formação continuada da escola pesquisada constitui-se em uma parte viva de seu projeto educativo e se referencia por indícios de criatividade mais acentuados na liderança estimulante e criativa, no professorado criativo e na visão transdisciplinar e transformadora.
\end{abstract}

Palavras-chave: Criatividade. Formação continuada. Ensino Fundamental.

\section{FORMACIÓN CONTINUA DE PROFESORES EDUCACIÓN FUNDAMENTAL: UN DESAFIO CREATIVO EN LA CULTURA CONTEMPORÁNEA}

\begin{abstract}
Resumen. Este artículo tiene como objetivo analizar la formación continua de los profesores de la enseñanza fundamental de la Escuela Municipal Tiempo Integral Daniel Batista (Tocantins - Brazil), considerando indicadores del Instrumento de Identificación de Desarrollo Creativo de Instituciones de Enseñaza (Vadecrie). El referencial metodológico cualitativo se ha apoyado en el estudio de caso y en las investigaciones exploratoria y documental. Para la recogida de datos, la aplicación del Vadecrie ha sido complementada con la realización de una entrevista cuasi estructurada, observación de campo y análisis documental. Los resultados indican que la formación continua ocurre a partir de las necesidades locales y que el profesorado es protagonista de su formación, posibilitando a la institución profundizar en sus potencialidades y superar adversidades. En ese sentido, la formación continua en la escuela investigada se caracteriza por ser una parte viva de su proyecto educativo y se expresa por indicios de creatividad más acentuados en el liderazgo estimulante y creativo, en el profesorado creativo y en una visión transdisciplinar y transformadora.
\end{abstract}

Palabras clave: La creatividad. Educación continua. Enseñanza fundamental. 


\title{
CONTINUING FORMATION OF FUNDAMENTAL EDUCATION TEACHERS: A CREATIVE CHALLENGE IN CONTEMPORARY
}

\begin{abstract}
This article aims to analyze the lifelong training of teachers of elementary school at the Municipal School Tempo Integral Daniel Batista (Tocantins - Brazil), considering indicators contained at the Identification of Creative Development of Educational Institutions' instrument (Vadecrie). The qualitative methodological framework is supported in the case study and in the exploration and documentary analysis. For data collection, the results of Vadecrie have been complemented with a structured interview, field observation and document analysis. The results indicate that lifelong training comes from local needs and that educators are the protagonists of their training, enabling the institution to deepen their potential and overcome adversity. With this regard, training at the school investigated is characterized as a living part of its educational project and it is best expressed in by signs of more pronounced creatively, stimulating and creative leadership, creative educators and a transdisciplinary and transformative vision.
\end{abstract}

Keywords: Creativity. Continuing formation. Elementary School.

\section{Introdução}

$\mathrm{Na}$ sociedade contemporânea são muitos os desafios que se colocam na formação continuada de professores, uma vez que essa exige uma reflexão pessoal e coletiva. E isso implica, múltiplos olhares, discussões, opiniões e reflexões progressivas da escola como lócus de formação. Esse processo formativo se faz urgente, requer uma formação crítica e criativa, na qual os professores sejam sujeitos construtores de novas possibilidades do aprender e do ensinar.

Nesse entendimento, Torre $(2013$, p. 145) percebe a “... criatividade como valor social e cultural que deveria ser assumida pelas organizações socioculturais e instituições educativas". A criatividade é essencial para haver mudança no contexto educacional; todavia, necessita ser vista de forma social e não individual.

Em face disso, a escola enquanto instituição educacional na sociedade atual precisa, urgentemente, de práticas pedagógicas pautadas na transformação do sujeito, atitudes de responsabilidade e autonomia, buscando a construção do conhecimento em sua totalidade. Tal ação no âmbito escolar requer uma formação continuada e contextualizada dos professores, pois essa inquietação e consciência da necessidade de procurar novos saberes são possibilidades para solucionar os problemas no espaço de sala de aula.

Nóvoa (2009, p. 19) sinaliza a urgência de os professores serem autores de sua formação, pois “... nossas propostas teóricas de formação continuada de professores só fazem sentido se forem construídas dentro da profissão, se forem apropriadas a partir de uma reflexão dos professores sobre o seu próprio trabalho.” Dessa forma, esperamos que a formação continuada possibilite que os professores se reconheçam como profissionais em permanente aprendizagem e se sintam parte do processo, 
desenvolvendo uma visão integradora na busca pela articulação religação ao conhecimento (Suanno, M., 2013).

Nesse contexto, apresentamos resultados finais da pesquisa de mestrado do Programa de Pós-Graduação em Educação (PPGE), da Universidade Federal do Tocatins (UFT), campus de Palmas. O objetivo de tal estudo e, por consequência, deste artigo é analisar a formação continuada dos professores do Ensino Fundamental da Escola Municipal de Tempo Integral Daniel Batista a partir dos indicadores Vadecrie.

A motivação para o desenvolvimento de estudos a respeito dessa temática, a qual se justifica pela relevância da prática criativa no processo de formação de professores, e ainda, por minhas experiências como docente dos anos iniciais do Ensino Fundamental, tem em seu cerne a importância da criatividade no contexto educacional

Observa-se que a contemporaneidade vem sendo marcada por grandes mudanças científicas, tecnológicas e planetárias; tais modificações afetam a dimensão social, ambiental, econômica e cultural. Diante disso, é urgente a inserção de uma formação contínua de professores pautada na criatividade, levando à construção de novas formas de aprender e ensinar. Essa concepção implica, primeiramente, perceber que a sociedade evolui constantemente e, por isso, requer transformações na compreensão de mundo, no conhecimento. Mas ela demanda, principalmente, que os professores tenham consciência da necessidade e importância da constante formação para mudanças de práticas e renovação do saber, de forma que seja pautada em ações criativas.

Diante desse contexto, percebemos que muitos são os desafios enfrentados pela educação brasileira. No âmbito escolar não é diferente, ele necessita de alterações tanto no espaço físico quanto nas práticas escolares. Sob esse prisma, Torre (2008) define a criatividade como uma condição e atitude que todo o ser humano precisa para resolver os diversos problemas da educação. Ainda na dimensão da criatividade, o autor afirma que tem uma "... conotação científica e social. Nela o significado pessoal e o alcance social não são menos relevantes que o científico." (Torre, 2005, p. 15). A criatividade é definida pelo autor como um bem social, compreendida como um conjunto de valores e bens de serviços, que necessitam ser compartilhados pelos membros de uma sociedade e reconhecidos pela cientificidade (Torre, 2005).

Partindo desse pressuposto, faz-se indispensável que a formação de professores inicie pela perspectiva da criatividade. Isso decorre da importância dessa temática para as mudanças da formação humana como princípio de produção do conhecimento na contemporaneidade.

Sob esse olhar, a grande necessidade da sociedade atual é o desenvolvimento da criatividade nas pessoas, principalmente no contexto escolar. Contudo, segundo Araújo (2009), pouco se tem estimulado nos alunos o pensar criativo, cujas características são: persistência, autoconfiança, independência, disposição e capacidade de pensar novas ações para os problemas. Esses traços exigem que a aprendizagem parta dos próprios erros para possibilitar maior compreensão das dificuldades. 
Torre (2005) aponta a necessidade da divulgação do conceito, bem como da fundamentação em concepções coerentes e sistematizadas. Tal premissa torna indispensável a compreensão das diferentes percepções do termo 'criatividade' para buscar um trabalho compartilhado e criativo.

Percebemos a necessidade de investimento na formação dos professores para que possam conhecer e estimular a criatividade, em primeiro lugar, em si mesmos, para depois desenvolvê-la em sala de aula, abrindo, dessa forma, diferentes caminhos para múltiplas descobertas (Wechsler e Nakano, 2011). Ainda conforme os referidos autores, a formação apresenta lacunas, uma vez que tende a enfatizar conhecimentos já adquiridos e não busca desenvolver novas formas para solucionar os problemas que surgem no caminhar da ação do professor. Com isso, a criatividade faz-se necessária tanto nas atitudes dos docentes quanto em suas estratégias de ensino utilizadas em sala de aula.

Diante do exposto, compreendemos a necessidade de o processo educativo ter atividades que desenvolvam nos alunos a capacidade da autonomia na aprendizagem e na vida. Para tanto, os professores devem ter consciência, vontade e, sobretudo, formação continuada para alcançar uma educação criativa.

Na busca por uma educação criativa, são essenciais constantes mudanças no pensar, dimensionar, compreender e interpretar a realidade em que se vive. Torre (2005, p. 40) indica que toda a mudança promovida

... na educação deveria ser assumida pelo professorado. Não fazê-lo é jogar com as palavras sem que estas cheguem a mudar a realidade. Se quisermos que a criatividade faça parte da educação, temos que antes formar os professores nela atendendo a três dimensões do conhecimento, habilidades e atitudes. Somente quando o professor toma consciência do valor da criatividade com respeito a formação, podemos pensar em mudança em nível curricular.

Como exposto, o professor precisa ter consciência da importância da criatividade na formação, pois, a partir desse entendimento, é possível pensar uma mudança na perspectiva da formação continuada. Para isso, os docentes carecem privilegiar conteúdos relacionados à criatividade, pois um dos desafios da formação continuada, na atualidade, é criar oportunidades de aprendizagem que favoreçam o desenvolvimento do potencial criativo dos professores (Fleith, 2011).

Para que o ato criativo ocorra de forma gradual, é necessário que esse processo seja inserido no âmbito educativo desde o início da formação profissional. Assim, passa-se a compreender a dimensão formativa como condição indispensável para as mudanças da realidade educacional.

Partindo desse ponto de vista, são imprescindíveis atividades criativas na escola, sobretudo na contemporaneidade, período que realça a urgência de transformações nas instituições de ensino. Desse modo, são elaborados projetos com mudanças físicas e 
pedagógicas. Também percebemos a importância da inserção da criatividade nos planejamentos de cada professor, com o objetivo de solucionar os problemas, bem como de realizar diferentes estratégias para o desenvolvimento das atividades docentes.

Diante dessa acepção, notamos que o professor criativo está constantemente buscando estratégias pedagógicas para o aprender e ensinar. O docente, com princípios criativos, preocupa-se com seu entorno e ainda procura desenvolver um trabalho compartilhado para a transformação da sociedade. Cabe ressaltar que o trabalho compartilhado é imprescindível na perspectiva da criatividade, uma vez que requer um fazer pedagógico voltado às necessidades da escola e ao respeito às diversas opiniões, conhecimentos, experiências e transformações.

O trabalho coletivo é fundamental para que a mudança ocorra de forma global, envolvendo os sujeitos que atuam em uma mesma instituição. Para tanto, o processo formativo não pode se configurar como ações isoladas ou esporádicas, ou seja, precisa que os professores estejam sempre abertos a novas discussões para permitir a prática efetiva da criatividade.

Ainda na dimensão da importância da criatividade para a formação do educador, Zwierewicz (2012) atesta que o ato criativo é uma premissa de sobrevivência planetária. Isso indica que, na atualidade, é cada vez mais urgente a realização de um trabalho docente que busque diariamente ações pautadas nos valores da criatividade.

Mas viver na perspectiva da criatividade significa ir além do conhecimento dos conteúdos, deve-se ter curiosidade, imaginação, bem como buscar a construção de novos conhecimentos e, sobretudo, contribuir para uma educação mais criativa e significativa. Cabe salientar que a criatividade consiste “... em uma visão singular do mundo que se faz acompanhar da emoção e isso ajuda o ser humano a refletir sobre a realidade. Portanto, é somente a partir das experiências e dos conhecimentos anteriores que é possível criar.” (Carneiro, 2013, p. 137).

É indispensável, portanto, que os professores tenham clareza de que o processo criativo não se inicia espontaneamente; ele carece de uma aproximação das ideias anteriores para que seja possível ressignificá-las, em seu fazer pedagógico, em sala de aula. Para que isso ocorra, Fleith $(2011$, p. 46) sinaliza a relevância de “... capacitar o professor a criar condições em sala favoráveis ao desenvolvimento da criatividade e levá-lo a refletir sobre sua prática docente".

Nesse sentido, os pesquisadores brasileiros membros da Rede Internacional de Escolas Criativas (RIEC) têm realizado várias pesquisas na dimensão do ensinar e do aprender. A RIEC

... compreende que as escolas criativas são instituições que tem características superadoras das práticas instituídas e naturalizadas nas escolas, por isso transcendem, pois são instituições que recriam suas concepções e fundamentos, valores e práticas. Assim, buscam transformar as pessoas, os projetos e 
processos escolares, os contextos e a realidade social. (Suanno, M., Torre e Suanno J., 2014, p. 21).

Para que se construa uma prática criativa na dimensão social, faz-se imprescindível a construção de potencialidades humanas e a busca de soluções de problemas na educação. Essas ações implicam, primeiramente, mudança na formação de professores para que esses tenham pensamentos e atitudes ampliadas ao desenvolver atividades criativas com seus alunos, propiciando-lhes novos caminhos e maneiras para agir na vida pessoal e profissional.

Como podemos perceber, é urgente que a escola atual busque uma formação pautada nos valores da criatividade. Isso implica atentar também para a fundamentação da ecoformação e da transdisciplinaridade para propiciar um conhecimento integral dos sujeitos. Torre, Pujol e Moraes (2008, p. 21) compreendem a ecoformação "como uma matéria sintética, integradora e sustentável de entender a ação formativa, sempre em relação ao sujeito, à sociedade e à natureza".

Seguindo essa mesma linha de pensamento, Suanno, J. (2013, p. 157) reforça que na contemporaneidade é cada vez mais urgente que os professores estejam conscientes de seu "... importante papel na ação formativa do sujeito e da sociedade em relação à sua interação com a natureza e os meios de realizar uma inteligência sadia e duradoura, que perpetue o bem-estar pessoal e social com o ambiente". Dessa forma, consolida-se a busca por uma formação comprometida com o ser humano, com a sociedade e a natureza, e atenta aos saberes que estejam interligados com e para a vida.

Portanto, a contemporaneidade implica uma formação pautada nos valores da criatividade, bem como a percepção de nós mesmos, do entorno e da sociedade a nossa volta. O período atual também demanda sujeitos que consigam compreender esse processo de forma integradora para fomentar um conhecimento integral, que prime pela interligação dos diversos saberes. Essa compreensão é necessária e urgente ao enfrentamento das adversidades na vida pessoal e profissional e na tomada de consciência do valor da criatividade para as transformações, além de ser indispensável para que sejam ressiginificados o aprender e o fazer do professor no contexto educacional.

Parte-se do princípio de que os desafios formativos na contemporaneidade têm implicações e são influenciados pelas transformações sociais, políticas e econômicas, que têm propiciado mudanças cada vez maiores no ritmo de vida das pessoas. Essas modificações implicam todas as áreas da educação, pois são muitos os desafios dessas novas formas de pensar e fazer, sobretudo na dinâmica da formação continuada de professores.

Imbernón (2011, p. 55) afirma que “... uma formação deve propor um processo que dote o professor de conhecimentos, habilidades e atitudes para criar profissionais reflexivos ou investigadores". Isso implica considerar a escola como lócus de formação e levar em conta a responsabilidade do professor de se assumir como produtor de sua 
formação (Nóvoa, 1992). Para que se possa ter uma formação investigativa e criativa, deve haver a mudança da concepção de formação. Esta, muitas vezes, é realizada apenas por meio de cursos pontuais, sem considerar a alteração das realidades dos professores e, sobretudo, seu fazer docente.

O desafio que se coloca para a formação é que não se restrinja, apenas, a ofertas pontuais ou exigências operativas da Secretaria da Educação. Ela precisa acontecer em todo o espaço educacional e incluir todos os docentes, levando à transformação permanente das práticas pedagógicas. Assim, a formação continuada no âmbito escolar passa a ser parte viva do projeto educativo da instituição, partindo também das experiências dos professores.

Davis e outros (2014, p. 14) afirmam que na formação no âmbito escolar “... só faz sentido propor os programas de formação continuada se eles forem capazes de desencadear as mudanças pertinentes e necessárias nas escolas, capazes de auxiliá-las a atender mais e melhor sua clientela". Em face disso, é possível compreender que a formação continuada carece ir além dos problemas do cotidiano escolar, necessita de uma ampla visão do processo que a concebe.

Em consonância com o exposto, Imbernón (2011) indica que a formação centrada na escola parte da compreensão de um trabalho compartilhado pelo grupo de professores, refletindo, concomitantemente, as estratégias para solucionar os problemas do âmbito educativo, na busca de um ensino que forme alunos e alunas em sua totalidade. $\mathrm{O}$ autor salienta como a formação continuada necessita ser pensada em seu sentido amplo, sendo decidida e planejada pelo conjunto de seus pares. Com isso, os professores se tornam sujeitos de suas práticas: investigam os contextos em que atuam e propiciam a troca de experiências diárias a respeito do que acontece na sala de aula e na escola como um todo. Essas informações demostram que a formação continuada, nesse viés, tem relação com a perspectiva criativa, além de representar uma constante busca para a construção de novas práticas educacionais.

Contudo, refletir novas maneiras para a formação continuada, implica entender que o saber é social, uma vez que é partilhado por todo um grupo de professores e composto por práticas que são objetos coletivos.

Desse modo, o processo formativo centrado no espaço escolar pressupõe a formação docente criativa, visando práticas pautadas nos diferentes saberes, na busca de novos caminhos para o fazer do professor. Nessa perspectiva, Nóvoa (1992) compreende que a mudança educacional está relacionada à formação do professor e às transformações das práticas pedagógicas, pois necessita se associar aos projetos educativos da escola.

Partindo desse pressuposto, faz-se indispensável que os professores sejam protagonistas de sua formação. Eles devem se configurar como agentes de transformação das realidades educativas, que percebem esse espaço como lugar de criação e permanente aprendizagem para professores e alunos. 


\section{Método}

A pesquisa fundamentou-se metodologicamente pela abordagem de natureza qualitativa exploratória (Gil, 2012), do tipo estudo de caso. Assim, o tipo de estudo supracitado, caracteriza-se como uns dos tipos de pesquisa que investiga um fenômeno atual dentro de seu contexto de realidade, quando as fronteiras entre o fenômeno e o contexto não são claramente definidas, e utiliza várias fontes de evidências para serem analisadas e interpretadas (André, 2013).

O método adotado para esta pesquisa foi o estudo de caso. De acordo com Yin (2010), esse caminho metodológico busca entender profundamente o fenômeno contemporâneo no contexto de vida real. Possibilita a investigação nos aspectos globais, complexos, parciais e individuais do objeto pesquisado. Para tanto, a coleta dos dados foi utilizada a observação direta em campo e o questionário Vadecrie, além de entrevista e análise de documentos institucionais.

A pesquisa fundamentou-se metodologicamente no enfoque qualitativo, com apoio dos métodos documental, exploratório (Gil, 2012) e estudo de caso (André, 2013). Para a coleta dos dados foi utilizada a observação direta em campo e o questionário Vadecrie, além de entrevista e análise de documentos institucionais.

A partir desses pressupostos, a questão principal que norteou o estudo foi: há indícios de criatividade na formação continuada dos professores do Ensino Fundamental da Escola Municipal de Tempo Integral Daniel Batista, de acordo os indicadores Vadecrie?

Com a finalidade de responder a tal problemática, foi realizado um levantamento dos cursos de formação continuada previstos no Projeto Pedagógico do Curso (PPP) da escola pesquisada - anos 2013 e 2014 - e a análise de documentos que evidenciam a realização da referida formação na instituição, no período de agosto de 2012 a maio de 2015.. Destaca-se que a importância da análise documental é reconhecida por Gil (2012) e por Lüdke (1986), sendo que o último a situa como uma técnica de relevância para a pesquisa qualitativa por complementar as informações obtidas por meio de outros recursos, contribuindo para desvelar novos aspectos de um tema ou problema. 
A técnica da observação, por sua vez, possibilita ao pesquisador perceber, sobretudo, aquilo que não é dito, mas que pode ser visto e compreendido por um observador atento e persistente, além de fornecer o maior número de informações sobre o tema em questão (Gil, 2012). Após a observação de rotinas institucionais, foi aplicado o questionário Vadecrie ${ }^{1}$ a professores, gestores, pais e a alunos do $1^{\circ}$ ao $9^{\circ}$ ano do Ensino Fundamental.

Depois das etapas descritas, foram entrevistamos alguns professores e gestores do Ensino Fundamental que participaram da formação e responderam ao questionário. O diálogo se estabeleceu com quatro professores ${ }^{2}$ do Ensino Fundamental $-1^{\circ}, 5^{\circ}, 6^{\circ}$ e $9^{\circ}$ ano -, duas coordenadoras (anos iniciais e anos finais) e a diretora da Unidade de Ensino. Na sequência, foi realizada uma observação complementar na sala de aula dos quatro professores que participaram da entrevista, buscando identificar as ações criativas desenvolvidas na docência após a participação na formação continuada.

O total de sujeitos que participou da amostra foi 135 (professores, gestores, pais e alunos). Essa multiplicidade de sujeitos e grupos estudados se deve ao intuito de elucidar as compreensões de professores, gestores e pais acerca da criatividade na formação continuada de professores, a partir dos seguintes indicadores do questionário Vadecrie: Liderança estimulante e criativa, Professorado criativo, Criatividade como valor e Visão transdisciplinar e transformadora.

$\mathrm{Na}$ sistematização dos resultados foi preservada a identidade dos sujeitos pesquisados $^{3}$. No caso dos estudantes, essa condição teve uma atenção especial porque se tratavam de menores de idade. Destaca-se ainda que nas respostas os alunos forram identificados pela letra A, os professores pela letra $\mathrm{P}$ e os gestores pela letra $\mathrm{G}$.

Por compreendemos a criatividade como caminho de mudança na educação e, sobretudo, na perspectiva da formação de professores, buscamos perceber os indícios de criatividade na formação continuada dos professores do Ensino Fundamental dessa Unidade de Ensino, bem como verificar se tal formação é realizada na perspectiva dos quatro indicadores como parâmetro de análise deste estudo.

Para desdobrar os pressupostos estabelecidos, analisamos o conceito de criatividade e sua relevância na formação continuada de professores do Ensino

\footnotetext{
${ }^{1}$ O questionário VADECRIE é um instrumento de coleta de dados que permite a análise qualitativa das respostas para o melhor diagnóstico dos resultados, ou seja, dos indícios de criatividade na formação continuada dos professores (SUANNO, J., 2013). Esse instrumento foi elaborado pelo professor Saturnino de la Torre com a parceria de pesquisadores da América Latina e da Europa e possui dez parâmetros ou categorias constitutivas de uma instituição educacional (TORRE, 2009). São eles: Liderança estimuladora e criativa; Professorado criativo; Cultura inovadora; Criatividade como valor. Espírito empreendedor; Visão transdisciplinar e transformadora; Currículo polivalente; Metodologia inovadora; Avaliação formadora e transformadora; e Valores humanos, sociais e ambientais.

${ }^{2} \mathrm{O}$ Termo de Consentimento Livre e Esclarecido (TCLE) foi assinado pelos entrevistados com todas as informações a respeito dos procedimentos adotados durante a condução da pesquisa.

${ }^{3}$ Este estudo assumiu as disposições contidas na Resolução do Conselho Nacional de Saúde ${ }^{\circ}$ 196/96, sobretudo no que diz respeito à ética na pesquisa com seres humanos. Portanto, esta pesquisa foi submetida ao Comitê de Ética em Pesquisa da UFT e aprovada por esse conselho
} 
Fundamental. Em seguida, buscamos compreender a dimensão formativa na contemporaneidade, bem como seus desdobramentos no contexto escolar, com a finalidade de relacionar os antecedentes teóricos com os dados coletados. Nesse sentido, acreditamos que a pesquisa trata de um tema indispensável na dimensão educativa na atualidade.

\section{Resultados e discussão}

\section{- Formação continuada de professores da Escola Daniel Batista: desafios e perspectivas}

No que concerne à análise documental, caracterizamos o Projeto Político Pedagógico (PPP) da Escola Daniel Batista como instrumento que busca atender às necessidades pedagógicas dessa instituição (Escola Municipal de Tempo Integral Daniel Batista, 2014). Para entender esse aspecto, podemos reconhecer a validade dos aspectos explorados por Nóvoa $(1992,1999)$ quando assegura a necessidade dos professores reconhecerem a escola como lócus de formação e, sobretudo, de se assumirem como protagonistas dessa ação. Assim, a formação continuada de professores deve ser diversificada tanto nos modelos quanto nas práticas.

Partindo desse pressuposto e da formação do contexto escolar, os professores procuram aprender metodologias criativas, capazes de suscitar uma educação crítica nos educandos. Elas devem ser relacionadas aos conteúdos e aos saberes para a vida. Nesse viés, as entrevistadas sinalizam a importância de o desenvolvimento da formação ocorrer a partir das necessidades da escola:

Acho que essa formação sendo feita por nós mesmos, ela tem um valor especial, tem mais atenção, porque a gente está discutindo um problema que é nosso, que todo mundo quer uma solução, então assim, as pessoas se interessam mais nas discussões. (G2, 2015).

Olha, a formação continuada ela veio de alcance ao professor, que aqueles professores que estudaram o tempo do tradicionalismo que era a decoreba em si, como os autores falam... O professor faz uma formação, ele tem que mudar as suas atitudes, a observar a necessidade que hoje na sala de aula requer do professor, que ele busque novas ações. (P1, 2015).

Nos relatos das entrevistadas podemos constatar a importância da formação para as transformações da educação e das práticas pedagógicas, bem como da necessidade de aprender novas concepções para a modificação das ações na sala de aula. Essa percepção corrobora com as ideias dos autores de apoio desta pesquisa.

Contudo, cabe salientar que, mesmo almejando uma formação construída pelo saber de seus pares, esse projeto esbarra em dificuldades referentes ao registro dessa ação. De acordo com as gestoras, essa é uma das dificuldades que precisam superar. Sobre essa sistematização das ações da formação, uma das gestoras afirmou: 
A gente tem que fazer também, bem falado, precisa fazer de cada uma porque quando a gente vai nessas viagens internacionais, tem que fazer todo o relatório da viagem, das palestras e é interessante até mesmo para o professor começar a registrar e para ter aquela prática mesmo, porque tudo é prática, se a gente tem prática de registro, vai começar a fazer. (G3, 2015).

Nesse viés, Nóvoa (2009, p. 40) sinaliza que “... o registro escrito tanto das vivências pessoais quanto das práticas profissionais é essencial para que cada um adquira uma maior consciência do seu trabalho e da sua identidade como professor".

Com respaldo nas entrevistas dos professores e dos gestores, deduzimos que são imprescindíveis as práticas pedagógicas pautadas na dimensão global do sujeito. Essa ação pressupõe disposição do educador no processo de ensino e aprendizagem, para ultrapassar a forma linear e fragmentada de ensinar e aprender, ou seja, para imprimir um olhar abrangente das dimensões educativas.

Assim, podemos considerar que a motivação dos professores na realização da formação continuada se dá a partir dos problemas e dos anseios e que essa ação da instituição tem o apoio da equipe gestora (direção e coordenação). Os dados coletados revelam a presença do indicador Liderança estimulante e criativa, uma vez que há um trabalho compartilhado e facilitador dos projetos e das ações dos professores na busca de práticas criativas para a aprendizagem.

Identificamos ainda, nas observações dessas formações, o indicador Professorado criativo. Os professores possuem espírito criativo e atitude aberta, flexível e colaborativa. Pensam sua própria formação na busca de novos conhecimentos para o fazer em sala de aula e compreendem que os saberes são para a vida.

\section{Percepção dos professores, gestores, pais e alunos}

Nas análises do instrumento de coleta de dados Vadecrie estudamos as respostas dadas pelos professores, gestores e pais/responsáveis da Escola Municipal de Tempo Integral Daniel Batista. Tivemos por finalidade diagnosticar a evidência ou ausência dos indicadores Vadecrie já mencionados, a saber: Liderança estimulante e criativa, Professorado criativo, Criatividade como valor e Visão transdisciplinar e transformadora (Torre, 2012). Utilizamos como referência a Tabela 1 para a análise qualitativa dos dados dos questionários dos gestores, professores e pais. 
Tabela 1. Valoração e conceitos

\begin{tabular}{|l|c|c|}
\hline \multicolumn{1}{|c|}{ Presença do indicador } & $\begin{array}{c}\text { Valoração } \\
\text { Qualitativa }\end{array}$ & $\begin{array}{c}\text { Valoração } \\
\text { Numérica }\end{array}$ \\
\hline Nunca ou quase nunca está presente & $\mathrm{D}$ & $1-2$ \\
\hline Às vezes se faz notar & $\mathrm{C}$ & $3-4-5$ \\
\hline Em muitas ocasiões existem evidências do indicador & $\mathrm{B}$ & $6-7-8$ \\
\hline Continuamente há evidências claras do indicador & $\mathrm{A}$ & $9-10$ \\
\hline
\end{tabular}

Fonte: Adaptado de Suanno, J. (2013)

Com respaldo em Suanno, J. (2013) para identificar as evidências criativas na formação continuada da Escola Daniel Batista, a análise dos indicadores nos questionários foi realizada com notas de zero a dez (avaliação numérica) e com conceitos de A a D (avaliação qualitativa). Tomamos como critério de avaliação, nesta pesquisa, os quatro indicadores para identificar a compreensão de professores, gestores e pais. Para haver indícios de criatividade na dimensão da formação continuada dessa Unidade de Ensino, é indispensável evidenciar, por meio dos questionários, no mínimo, o conceito B ou a nota seis, conforme descrito na Tabela 1.

$\mathrm{Na}$ percepção dos professores e gestores, a gestão tem uma Liderança estimulante e criativa, que se evidencia no agrupamento A. Este é escolhido em 51,14\% das respostas desse indicador. No indicador Professorado criativo, atentamos para as trocas de conhecimento em relação ao que é desenvolvido na escola e à importância do uso da criatividade na formação continuada, propiciando, dessa forma, momentos de debates, discussões e trocas de experiências (Suanno, J., 2013). Os resultados podem ser verificados no gráfico a seguir:

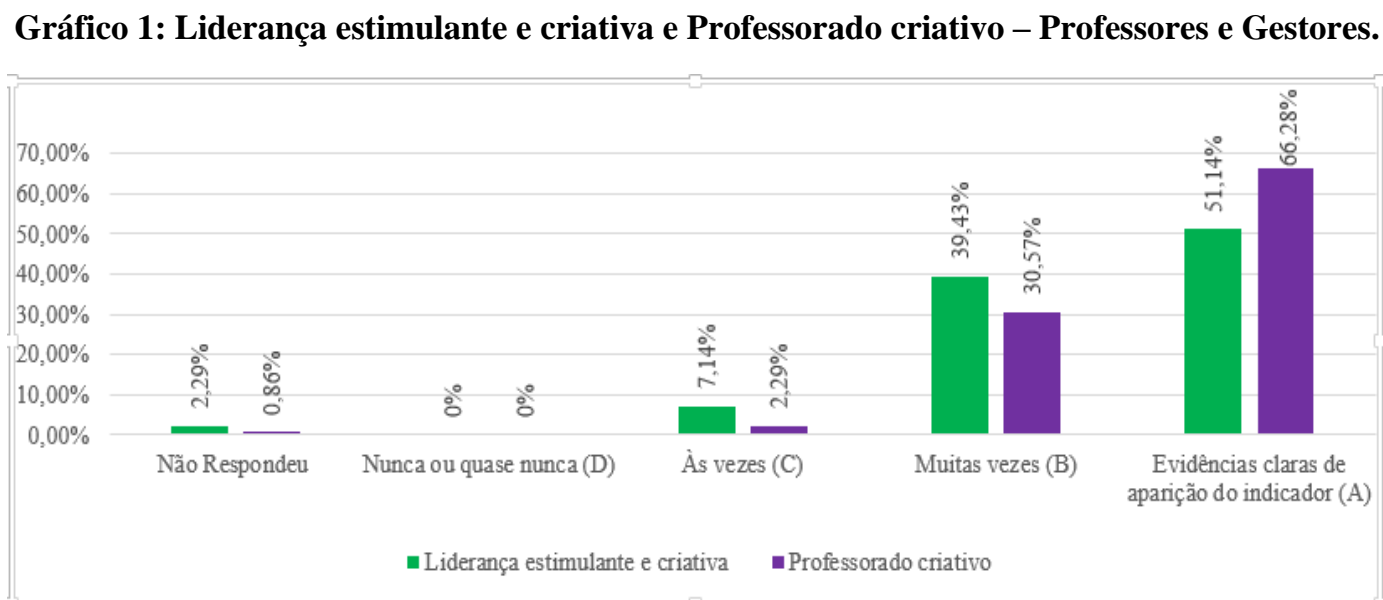

Fonte: Das autoras.

$\mathrm{Na}$ análise do indicador Criatividade como valor, objetivamos identificar na escola as particularidades de cada um dos alunos no uso da criatividade em 
planejamento, ações e projetos, bem como propiciar a eles debates e discussões que levassem em consideração seus interesses e sentimentos. Consideramos ainda, o desenvolvimento de projetos e ações que possibilitam educação de valores sociais a partir da vida e para a vida (Suanno, J., 2013). Esse aspecto foi avaliado com o conceito B (muitas vezes ou ocasiões) por $54,57 \%$ dos sujeitos. O gráfico a seguir revela as outras porcentagens da avaliação desse indicador e os dados relativos ao da Visão transformadora.

\section{Gráfico 2: Criatividade como valor e visão transdisciplinar e transformadora - Professores e} Gestores.

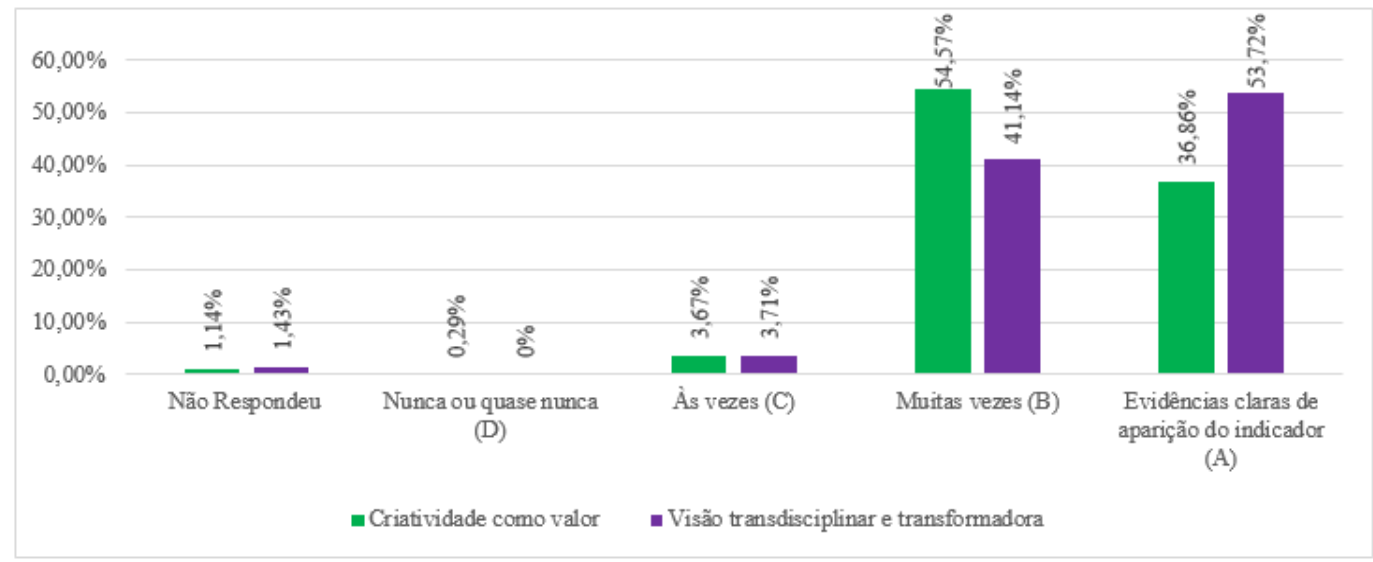

Fonte: Das autoras.

Na percepção dos pais, exposta no Gráfico 3, consta também uma Liderança estimulante e criativa e um Professorado Criativo:

Gráfico 3: Liderança estimulante e criativa e Professorado criativo - Pais.

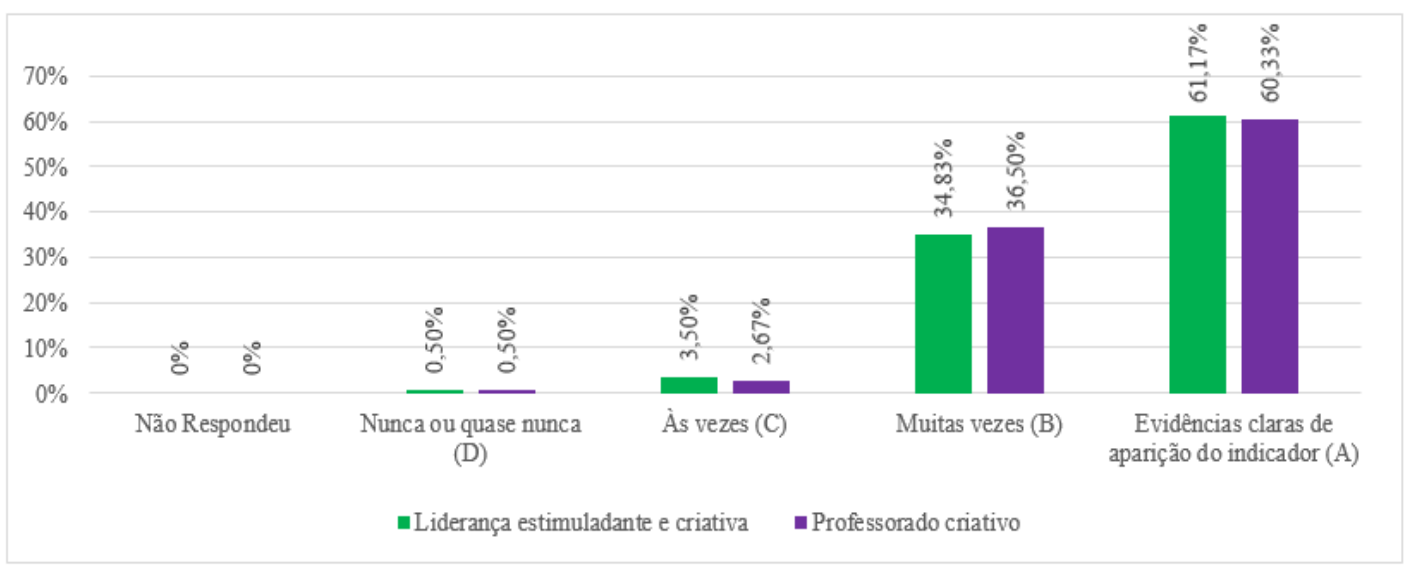

Fonte: Das autoras.

A percepção dos pais em relação ao indicador Liderança estimulante criativa é visível. Eles reconhecem uma gestão comprometida e compartilhada, impulsionadora e 
facilitadora de projetos criativos, com evidências claras de aparição do indicador (conceito $A$ ), tendo $61,17 \%$ indicado esse parâmetro.

Com relação ao indicador Professorado criativo, constatamos que 60,33\% dos pais consideram que sua aparição se destaca (conceito $A$ ). Eles percebem que os professores têm atitude aberta, flexível, colaborativa e empreendedora e buscam a formação docente e discente em termos de competências para a vida.

Quanto aos indicadores Criatividade como valor e Visão Interdisciplinar, os pais apontaram que há evidências claras de aparição, ou seja, indicaram o conceito A, como mostra o Gráfico 4.

Gráfico 4: Criatividade como valor e visão transdisciplinar e transformadora - Pais

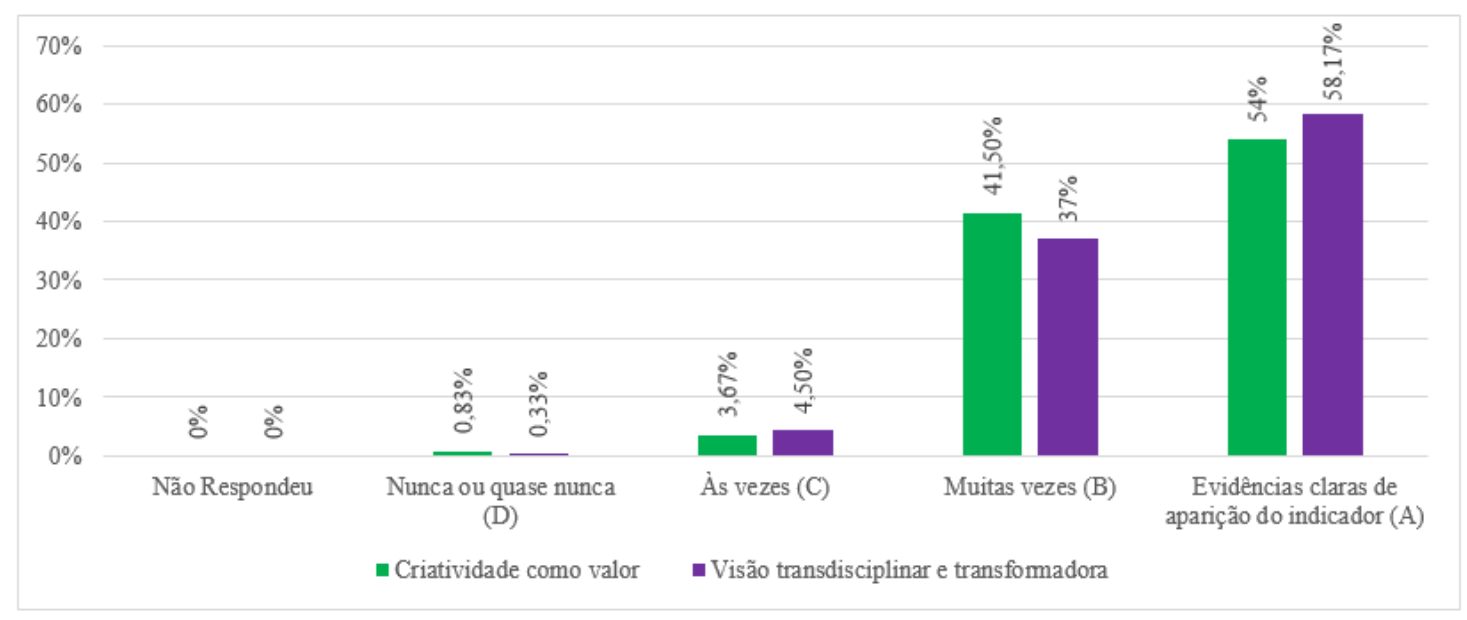

Fonte: Das autoras.

De acordo com os gráficos, os participantes de nossa pesquisa reconhecem que a Escola Daniel Batista possui acentuados indícios de criatividade na realização dos projetos e na formação continuada dos professores. Também indicam que a direção impulsiona o trabalho compartilhado na instituição, além de construir situações atrativas, originais, para as aulas.

As respostas dos questionários dos alunos também foram analisadas com base nos indicadores Vadecrie. Eles apresentaram as características que mais observavam na dimensão dos valores: carinho, prazer em aprender, interesse pelas disciplinas e reconhecimento das atividades, tanto no aspecto cognitivo quanto na importância para a vida. Solicitamos aos alunos que descrevessem, com relação aos professores, o que mais gostam. Os alunos assim se expressaram: "Gosto das atividades divertidas que eles fazem" (A1); "Eu gosto de quando eles chegam na sala de aula com uma aula diferente, com vontade de ensinar" (A2); "Sempre estão me ajudando a aprender mais" (A3).

Por meio dessas respostas, apreendemos a satisfação e o empenho dos alunos no trabalho realizado pelos professores. Isso se relaciona com os objetivos específicos do 
PPP, que tem como finalidade "... formar [um] cidadão participativo, responsável, crítico e criativo” (Escola Municipal de Tempo Integral Daniel Batista, 2013, p. 6).

Notamos a preocupação da instituição com o ambiente de respeito, e também, com a busca por uma convivência harmoniosa. Em virtude disso, solicitamos aos discentes que pensassem uma frase que revelasse seu sentimento em relação a seus professores. A5 escreveu: "Professores sábios que ensinam para a vida dos alunos serem melhores". Na percepção do aluno A6 o professor está entre a "sabedoria e a aprendizagem". Outros alunos afirmaram: "Meu professor é nota dez" (A7); "Os professores são muito especiais para nós" (A8); "Meus professores são legais" (A9). Feita a análise dessas frases, consideramos indispensável destacar a afirmação da aluna A5, que indica que o conhecimento vai além do aspecto cognitivo, pois os saberes são para a vida.

Outro ponto relevante dessa análise é a percepção dos alunos em relação às aulas. Eles indicaram o que pensaram ser interessante e por que. As disciplinas que mais se destacaram foram Matemática e Ciências. A aluna A8 diz que é a "Matemática, porque ela é muito legal" (A8). Para aluna A10, a "aula de Ciências, porque ela ensina sobre nosso corpo e ensina coisas que a gente não conhecia”. Percebemos ainda a compreensão que os alunos têm sobre o que as disciplinas representam em suas vidas. $\mathrm{O}$ discente A7 põe em destaque a aula de "Educação Física, porque ela ajuda a pessoa ter saúde". O ambiente da biblioteca também é tido como um espaço de muitos aprendizados, o que reforça a importância dos projetos de leitura desenvolvidos na escola.

$\mathrm{Na}$ contemporaneidade, muitos são os desafios que a sociedade tem enfrentado em relação à preservação da natureza. Nesse ponto, perguntamos o que os alunos têm aprendido na escola. A 11 respondeu: "Aprendo que não pode queimar a mata e nem matar os animais". A 13, por sua vez, afirmou que a natureza ... é muito importante para nossa vida, ela é importante para nós respirar. E sem a natureza teria só poluição".

Essa questão relaciona-se com o indicador Visão transdisciplinar $e$ transformadora. Nos relatos dos alunos é perceptível uma integração do conhecimento com as questões da vida e, sobretudo, com as consequências de suas atitudes para a natureza e todos os seres vivos que habitam a Terra.

Diante das declarações dos alunos, é possível identificarmos os quatro indicadores: Liderança estimulante, Professorado criativo, Criatividade como valor e Visão transdisciplinar e transformadora. Com isso, fica evidente que o professor ultrapassa o conteúdo, pois discute em sala de aula noções do aluno acerca da felicidade, do prazer em aprender e do carinho. Além disso, conecta os conteúdos escolares à vida, tornando-os significativos para os educados.

Passemos para as observações da sala de aula, estas incluíram turmas do $1^{\circ}$ e do $5^{\circ}$ ano dos anos iniciais e do $6^{\circ}$ e do $9^{\circ}$ ano dos anos finais do Ensino Fundamental. Como esta pesquisa busca indícios de criatividade na formação continuada dos 
professores da Escola Daniel Batista, foi necessário perceber ações criativas realizadas pelos docentes nessas turmas.

Com relação as análises na sala das turmas descritas, consideramos indispensável evidenciar a presença do indicador Liderança estimulante e criativa nas duas turmas dos anos iniciais e na última turma dos anos finais. Os professores propiciaram atividades que envolviam e facilitavam a aprendizagem dos alunos, além de impor limites e comprometimento na execução das tarefas.

Notamos que esses professores apresentam indícios de criatividade nas atividades realizadas, uma vez que o indicador Professorado criativo foi evidenciado em suas práticas. Esses aspectos foram revelados por meio das atividades realizadas em três turmas.

$\mathrm{Na}$ dimensão do indicador Visão transdisciplinar e transformadora, os professores trabalharam o sentimento e a emoção com os alunos, relacionando as atividades com a vida. Era notório o carinho entre docentes e discentes, mesmo quando se fazia necessário chamar a atenção dos alunos por conta de alguma ação inoportuna.

Pelas observações em sala, constatamos que a maioria dos professores consegue relacionar muitas das atividades realizadas com as temáticas trabalhadas nas formações. Esse aspecto foi evidenciado, principalmente, nas aulas que objetivavam instigar o aluno a ser protagonista de sua formação e buscar constantemente a criticidade e autonomia.

Diante disso, percebemos que a Escola Daniel Batista tem buscado uma formação que prima pelos aportes da criatividade, aspecto evidenciado no questionário Vadecrie, nas entrevistas, nas observações e nas análises dos documentos. Os dados ainda revelam indícios de criatividade na formação continuada de professores da Unidade de Ensino, a qual oportuniza um constante planejar e ressignificar de suas necessidades formativas no âmbito escolar.

\section{Considerações finais}

A fundamentação teórica aponta a necessidade de que se amplie a discussão sobre criatividade na dimensão educativa. Essa ação fomenta novos caminhos para a formação de professores, pois possibilita a construção diária de ideias originais e elaboração de projetos que potencializam o desenvolvimento de novas formas do aprender e do ensinar.

Acreditamos que seja indispensável formar professores com consciência e atitudes ampliadas para transformar situações adversas em ações criativas. Esses aspectos sinalizam que a criatividade carece ser assumida como um valor educativo e um bem social, para haver professores e estudantes criativos, atentando para as questões do entorno, ou seja, cidadãos que estão preocupados com a natureza e melhoria social como um todo (Torre, Pujol e Moraes, 2008). 
Buscar caminhos na contemporaneidade para potencializar a criação de espaços para a formação continuada de professores, implica um trabalho coletivo com base na partilha e no constante diálogo entre os pares, de modo que haja transformação nas práticas pedagógicas e, principalmente, um conhecimento articulado, crítico e criativo. Isso porque as ressignificações das ações docentes dependem que a formação dessa equipe contemple necessidades coletivas para a composição de novas aprendizagens. Quanto a essa questão, os dados evidenciam que a formação continuada da Escola Daniel Batista concebe o processo formativo de forma motivada, a partir das necessidades locais.

Ao triangular as informações obtidas nos instrumentos de coleta de dados aplicados aos pais, alunos, professores e gestores -, na análise dos documentos, entrevistas e observações, foi possível responder o pressuposto inicial da investigação. Com isso, chegamos à seguinte conclusão: a formação continuada no âmbito escolar é motivada, uma vez que os professores acreditam que sua realização propicia novas metodologias e uma aprendizagem significativa aos educandos, além de permitir o constante compartilhar entre a equipe docente. Dessa forma, salientarmos que os professores, em sua grande maioria, desenvolvem atividades com os alunos que desencadeiam mudanças de conduta em relação ao ambiente, ao outro e a toda a equipe educativa.

Compreendemos a criatividade como caminho de mudança na educação e, sobretudo, na formação de professores. Observamos que, para essa dimensão ter maior amplitude, necessita da divulgação dos resultados desta pesquisa às demais instituições de ensino, no intuito de propiciar aos professores, gestores e Secretaria de Educação a reflexão sobre a importância de a formação ser realizada a partir das necessidades e, principalmente, pautada na transdisciplinaridade e ecoformação. Esse foco formativo gera sujeitos preocupados consigo mesmos e com o contexto histórico, social, político, econômico, educacional e planetário.

Percebemos que as potencialidades alcançadas pela Unidade de Ensino investigada possibilitam a percepção da realidade, além de conduzir os professores a estarem atentos para a criação de novas maneiras de aprender e ensinar, na constante busca pela autonomia dos educandos e construção do conhecimento crítico e criativo.

Diante disso, podemos afirmar que a Escola Daniel Batista acredita que formar é tomar consciência das próprias atuações e buscar melhorá-las. Isso pode ser identificado na escola, pois os sujeitos que a integram primam por uma liderança criativa de professores e gestores, com autonomia para criar novas maneiras de potencializar os projetos e desenvolver aulas diferentes, com vistas a propiciar uma formação consciente, com valores éticos, sociais e ambientais.

Portanto, os resultados revelam que a formação continuada que a Unidade de Ensino pesquisada desenvolve, possibilita melhorar suas limitações, aperfeiçoar suas 
potencialidades. Além disso, ela contribui com uma prática criativa e transformadora das realidades educacionais.

\section{Referências}

André, M. E. D. A. de. (2013). O que é um estudo de caso qualitativo em educação. Revista da FAEEBA: educação e contemporaneidade. (pp. 95-103). Salvador, v. 22. $\quad$ n. $40 . \quad$ Recuperado de http://www.revistas.uneb.br/index.php/faeeba/article/viewFile/753/526, em 10 de junho de 2014.

Araújo, T. (2009). Criatividade na Educação. São Paulo: CPCD.

Carneiro, M. A. B. (2013). Criatividade: Potencial a ser desenvolvido em profissionais da Educação Infantil. In M. V. R Suanno, M. G. Dittrich E M. A. P. Maura (Org.). Resiliência, Criatividade e Inovação: potencialidades transdisciplinares na educação. (pp. 131-146). Goiânia: UEG/ED: América.

Davis, C. L. F. e outros. (2014). Formação continuada de professores: uma análise das modalidades e das práticas em estados e municípios brasileiros. São Paulo: Fundação Victor Civita.

Escola Municipal de Tempo Integral Daniel Batista. (2013). Projeto Político Pedagógico (PPP). Escola Municipal de Tempo Integral Daniel Batista. Palmas.

Fleith, D. de S. (2011). Desenvolvimento da criatividade na educação fundamental: teoria, pesquisa e prática. In S. M. Wechsler E V. L. T. Souza (Org.). Criatividade e aprendizagem: caminhos e descobertas em perspectiva internacional. (pp. 33-51). Campinas: Loyola.

Gil, Antonio Carlos. (2012). Métodos e técnicas de pesquisa social .6 ${ }^{\mathrm{a}}$. ed.. São Paulo: Atlas.

Imbernón, F. (2011). Formação docente e profissional: formar-se para a mudança e a incerteza. $9^{\mathrm{a}}$ ed. São Paulo: Cortez.

Lüdke, M. (1986). Pesquisa em Educação: abordagens qualitativas. São Paulo: EPU.

Nóvoa, A. (1992). A formação de professores e profissão docente. In: NÓVOA, A. Os professores e sua formação. Lisboa: Dom Quixote.

Nóvoa, A. (1999). O passado e o presente dos professores. In A. Nóvoa (Org.). Profissão professor. ( pp. 13-34). Tradução Irene Lima Mendes, Regina Correia e Luísa Santos Gil. Porto: Porto Editora.

Nóvoa, A. (2009). Professores: imagens do futuro presente. Lisboa: Educa.

Suanno, J. H. (2013). Escola Criativa e Práticas Pedagógicas Transdisciplinares e Ecoformadoras. 2013. 297 f. Tese de Doutorado em Educação. Universidade Católica de Brasília (UCB), Brasília. 
Suanno, M. V. R. (2013). Didática transdisciplinar emergente. In A. Santos, J. H. Suanno, J. H. E M. V.R. Suanno (Org.). Didática e formação de professores: complexidade e transdisciplinaridade. (pp. 23-49). Porto Alegre: Sulina.

Suanno, M. V. R.; Torre, S. de la; Suanno, J. H. (2014). Rede Internacional de Escolas Criativas. In M. J. Pinho, M. V. R. Suanno e E J. H. Suanno (Org.). Formação de professores e interdisciplinaridade: diálogo investigativo em construção. (pp. 15-31). Goiânia: América.

Torre, S. de la. (2008). Criatividade Aplicada: recursos para uma formação criativa. São Paulo: Madras.

Torre, S. de la. (2005). Dialogando com a criatividade: da identificação à criatividade paradoxal. Tradução Cristiana Mendes Rodríguez. São Paulo: Mandras.

Torre, S. de la. (2012). Instituciones educativas creativas. Instrumento para valorar el dessarrollo creativo de las Instituciones Educativas (VADECRIE). Barcelona: Editorial Círculo Rojo.

Torre, S. de la. (2013). Movimento de escolas criativas: fazendo parte da história de formação e transformação. In M. Zwierewicz (Org.). Criatividade e inovação no ensino superior: experiências latino-americanas e europeias em foco. (pp. 141 164). Florianópolis: Nova Letra.

Torre, S. de la. (2009). Rede de escolas criativas: em direção a uma escola do século XXI. In M. Zwierewicz E S. Torre (Coord.). Uma escola para o século XXI: escolas criativas e resiliência na educação. (pp.101-116). Florianópolis: Insular.

Torre, S. de la, Pujo, M. A. e Moraes, M. C. (2008). Transdisciplinaridade e ecoformação: um novo olhar sobre a educação. Tradução Susana Vidigal. São Paulo: TRIOM.

Wechsler, S. M.; Nakano, T. de C. (2011). Criatividade: encontrando soluções para os desafios educacionais. In S. M. Wechsler e V. T. Souza (Org.). Criatividade e aprendizagem: caminhos e descobertas em perspectiva internacional. (pp. 1131). Campinas: Loyola.

Yin, R. K. (2010). Estudo de caso: planejamento e métodos. 4ª ed. Tradução Ana Thorelll. Porto Alegre: Bookman.

Zwierewicz, M. (2012). Da adversidade à resiliência: o princípio motivador da escola criativa. In S. Torre, Saturnino e M. Zwierewicz (Coord.). Criatividade na adversidade - personagens que transformaram situações adversas em oportunidade. (pp. 49-60). Blumenau: Nova Letra. 
Data de recebimento: 10/05/2016

Data de revisão: 08/07/2016

Data do aceite: 20/07/2016 